\title{
Editorial: New Journal Title, Same Journal Mission
}

\author{
Bruce Sherin
}

Published online: 17 June 2011

(C) Springer Science+Business Media B.V. 2011

This issue marks a new phase in the evolution of this journal. As you can see the journal has a new title, Technology, Knowledge and Learning: Learning mathematics, science and the arts in the context of digital technologies. Despite the dramatic change to the title, the story is one of continuity, rather than discontinuity. For the last several years, our executive editors have sought to broaden the mission of the journal; most centrally, we have tried to move beyond a focus on mathematics to include a wider range of disciplines, especially science and the arts. Although it was easy for us to change our own conception of the mission of the journal, it has been quite difficult to alter how the mission is perceived by the wider world. We thus decided that we needed to send a stronger signal, and that a change to the title of the journal was the best way this could be accomplished.

Thus, in the minds of our editors, the core mission of our journal has not changed, just how we communicate this mission to the outside world. It is worth taking a moment to reiterate what that core is, and what makes TKL unique as a journal. Our new title mentions technology, knowledge, and learning. But TKL is not an "educational technology" journal in the usual sense. Part of the difference is that we are interested in uses of technology that push the envelope of what is possible. But, more than that, our core mission is grounded in the belief that novel technologies do not just provide a means of teaching the usual subject matter in a manner that is more effective, entertaining, or efficient. Rather, new technologies hold the potential to radically reshape what is taught and learned. That is why the words "technology," "knowledge," and "learning" together make up our title. It is not because the use of technology can lead to better knowledge and learning. It is because all three are tightly related and they change together. The bread and butter of TKL will always be articles that explore these tight interconnections.

This issue also marks a change in leadership of the journal. Uri Wilensky is stepping down as Editor-in-Chief after 6 years of leading the journal, and I will be taking his place. In addition, Andrea diSessa is stepping down as an executive editor. But here again the story is one of continuity rather than discontinuity. Aside from Andrea diSessa, the other

B. Sherin $(\bowtie)$

School of Education and Social Policy, Northwestern University,

2120 Campus Drive, Evanston, IL 60208, USA

e-mail: bsherin@northwestern.edu 
executive editors, including Uri Wilensky will continue in that role. In addition, two members of the larger editorial board, Michael Eisenberg and Lulu Healy, have agreed to serve as executive editors.

And, yes, it is fine to pronounce the new name as "tickle." 